until 1944, and the book became available to a wider public only in 1953 when the Akademie-Verlag, Berlin, published a German translation. By that time the stimulus provided by the Russian original had led to numerous new discoveries, some of which were added to the German translation in an appendix by B. H. Neumann. In the meanwhile, Kurosh himself had completely recast and revised his book in the light of the rapid advances, especially in the theory of infinite nilpotent groups, made by the powerful school of Russian group theorists. Thus, in the same year 1953, the second Russian edition appeared, virtually a now book compared with the first edition. It is from this second edition that Hirsch's translation was made. Once again Hirsch supplemented the translation by notes reporting on more recent developments. He also brought the bibliography up to date-that is, up to 1956so that it now includes more than 800 titles.

The theory of abelian groups, though part of general group theory, has its own methods and its own history of growth. A first account of the theory of infinite abelian groups appeared in 1954, in a wellknown monograph by I. Kaplansky. Here again further progress was rapid, and Fuchs's book in 1958 came none too early. Naturally, so far as the basic structure theory is concerned the books overlap. Beyond that much of the characteristic flavour of Fuchs's book is due to the fact that it, too, comes from the pen of one of a lively school of research workers in the subject, this time the Hungarian school of group theorists. Indeed, a glance at the extensive bibliography and at the numerous examples at the end of each chapter, many of them provided to give additional information on recent results in concise form, reveals the vigour of the (then) current research.

Both books start from the beginnings of the subject, assumir g no more than a certain maturity of mathematical reasoning and familiarity with some basic mathematical tools. Both lead to the frontiers of knowledge in their time, giving not only the latest results but also pointing again and again to the unsolved problems and open questions. Thus both books are suitable for, in fact strongly recommended to, the bright undergraduate and the young research student; at the same time their depth and scope make them indispensable for the expert. Some of the most striking discoveries made since their appearance owe much to the influence of these books; many of the problems they state are, in fact, now solved. Let us hope that a further edition may soon be possible.

By contrast, the book by Armand Borel and his collaborators deals with a highly specialized application of group theory and homology theory. It embodies the results of a seminar held by Borel at the Institute of Advanced Studies at Princeton, N.J.; several chapters are written by members of the seminar presenting their own contribution to its work. The topic is the application of cohomological methods to the study of the action of compact transformation groups on topological spaces; the tools, ranging far and wide over recent work in algebraic topology, are mainly taken for granted, though a general reference to the sources is provided. At this different level of specialization the presentation is again clear and well organized, but naturally concise. Each chapter carries its own short bibliography, not aiming at completeness but containing only the most reler ant papers. This book is clearly for the expert only.

\section{POWDER METALLURGY}

Fundamental Principles of Powder Metallurgy By Dr. W. D. Jones. Pp. xii +1032. (London : Edward Arnold (Publishers), Ltd., 1960.) 147s. net.

$\mathrm{P}$ OWDER metallurgy is becoming an increasingly important metallurgical process, and, though a number of comprehensive books on the subject have been published in the United States, it is very useful to have this long and detailed book published in Great Britain and written by an author with such wide experience in powder metallurgy. Dr. Jones is the author of the well-known book Principles of Powder Metallurgy published in 1937.

The now book starts with a long chapter of 239 pages on the preparation of powders and then has three chapters, totalling 350 pages, on "Pressing", "Shaping without Pressing" and "Sintering". These are followed by another very long chapter on "Attainment of Specific Qualities", which deals mainly with the properties required in products made by powder metallurgy, but which also contains a section on factory management. The book ends with two short chapters on "Continuous Powder Metallurgy" and "Methods of Control"; the former covers the three main methods of continuous compacting of powders; the latter is very short and merely lists the various methods of testing powders and compacts and states where details of the actual tests can be found.

The author states in his introduction that he intends to cover principles rather than practice and so detailed descriptions of plant and processes are not included. Apart from this omission the book is very comprehensive; very little, if anything, appears to have been left out. The book is written in a clear and simple manner with good and relevant illustrations.

The book will be essential for all metallurgical libraries, since some at least of the matters described will be of importance or interest to all metallurgists. It will also be useful to others who are not metallurgists, so important are powders in modern technology.

It is possible that with the development of processes such as the Sherritt-Gordon process for the reduction of metals from their ores, the final products of which are powders, powder metallurgical products will no longer be used only for small or specialized components but will also be used for large-scale processes.

As has been said, the book is long, more than a thousand pages, and at seven guineas is expensive. The length and cost could have been reduced by omitting parts which do not fall strictly within the province of powder metallurgy or which can be found in standard text-books. Examples are the descriptions of the properties of metal whiskers and of general magnetic properties. The section on "Powder Metallurgy as a Competitive Process" does not, as might be expected from its title, show when it is economical to use powder metallurgy rather than other processes, but describes the organization of a factory producing powder metallurgy products. The section is interesting, but it is doubtful whether the organization of such a factory differs in its essentials from any other factory producing small parts.

J. H. RENDALI 